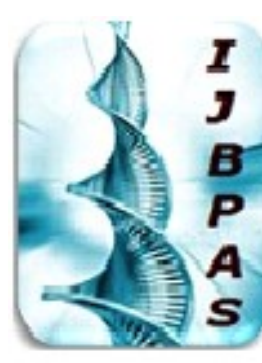

International Journal of Biology, Pharmacy and Allied Sciences (IJBPAS)

'A Bridge Betueen Caboratory and QRendo'

WwW.iibpas.com

Andrographis paniculata - A REVOLUTIONARY MEDICINAL PLANT

VORA $S^{*}$, PATEL K, BHATTACHARYA I AND GANGWANE A

Department of Biotechnology, Parul Institute of Applied Sciences, Parul University, Waghodia 391760, Gujarat, India

*Corresponding Author: Shreya Vora: E Mail: sddave08@gmail.com

Received $8^{\text {th }}$ Sept. 2020; Revised $11^{\text {th }}$ Oct. 2020; Accepted $13^{\text {th }}$ Nov. 2020; Available online $1^{\text {st }}$ Aug. 2021 https://doi.org/10.31032/IJBPAS/2021/10.8.5499

ABSTRACT

Andrographis paniculata (King of bitters), belongs to the Acanthaceae family. The objective of this study is to review the literature of Andrographis paniculata specifically have properties having therapeutic benefits, chemical properties and pharmacological evaluation. It is extensively used in indigenous system of medicines as home remedy for various diseases in ayurveda - an Indian traditional system of therapy. It is used to treat wide range of diseases including hepatitis, gastrointestinal tract and upper respiratory infections, fever, herpes, and a variety of other chronic and infectious diseases. Andrographis paniculata possess hepatoprotective, anti-inflammatory, immunostimulatory, antipyretic, antioxidant, hypotensive, antibacterial activities. Andrographis paniculatahas various phytochemicals like steroids, phenols, terpenoids, alkaloids, saponins, flavonoids as active compounds. The medicinal value of this plant is especially due to the presence of active phytochemical andrographolide which can be developed as phytomedicine.

Keywords: Andrographis paniculata, andrographolide, phytochemicals

\title{
INTRODUCTION
}

Andrographis paniculata, an Acanthaceae annual medicinal herb erect $128-130 \mathrm{~cm}$ found in the tropical parts of Asia including India, Bangladesh, China, Srilanka and Thailand. The herb shows 'Blood purifying' property with its relative usage in skin infections such as skin rashes, boils, scabies and chronic in-determined fevers since ancient times. The medicinal usage is inferred due to presence of various important chemicals in the aerial parts of plants [1] Mainly, 28 species of genus 
Andrographis Paniculata are found in the tropical Asia; among which Andrographis paniculata(Burm f.) Nees is the most popular specie with the desired property. It generally flourishes on all types of vegetative land mainly in pine, evergreen, deciduous and along roads and villages. Cultivation of Andrographis Paniculata is exercised on all types of soils regardless of the extremes. This plant exclusively grows

\begin{tabular}{|c|c|}
\hline \multicolumn{2}{|c|}{ Classification of A. Paniculata } \\
\hline Subkingdom & Tracheobionta - Vascular plants \\
\hline Superdivision & Spermatophyta - Seed plants \\
\hline Division & Magnoliaphyta - Flowering plant \\
\hline Class & Magnoliopsida - Dicotyledons \\
\hline Subclass & Asteridae \\
\hline Order & Scrophulariales \\
\hline Family & Acanthaceae \\
\hline Genus & $\begin{array}{c}\text { Andrographis wall. ex Nees - } \\
\text { false waterwillow }\end{array}$ \\
\hline Species & $\begin{array}{c}\text { Andrographis paniculata (Burm. } \\
\text { F.) Wall. ex Nees - Green chireta }\end{array}$ \\
\hline
\end{tabular}

in shady waste grounds, dry forests and in moist conditions [2]. It has been effectively used in traditional Chinese medicines and in at least 26 minimum formulations to treat disease conditions including fever, cold property herb to release body heat followed by efflux of toxins [1]. It is known as King of Bitters (English), Mahatikta (Sanskrit), Kariyatu (Gujarati), Mahatita (Hindi), Kalmegh (Bengali), or Fah Talai Jone (Thai), The Creat (English), Oli-kariyata (Marathi), Nilavembu (Telugu) [2].

Traditional application of Andrographis paniculata

The medical application of Andrographis Paniculata has played a vital role in traditional ayurvedic formulations due to presence various compounds such as diterpines, lactones and flavonoids. These chemicals constituting the important use which are predominantly found in the aerial parts such as leaves and roots considerably. Mainly leaves along with aerial parts were found rich in flavonoids, gums, mucilages, saponins, phytosteriods, and terepenoids upon screening through phytochemical test analysis. Aerial parts contain alkanes, ketones, aldehyde and lactones in 4 major forms like Andrographolide, deoxyandrographolide, neoandrographolide and 14deoxy-11, 12-didehydroan-drographolide $[1,3]$. Traditionally it has been in an application for various disease conditions; the extreme bitter taste is due to Andrographolide content which through review shows potent antioxidant, hepatoprotective, antimicrobial, anticancer, antivenom, anti HIV, antimalarial, antipyretic, antifertility, antidiarrhoeal, antidiabetic, antihipe-rlipidemic activities [4-8]. Andrographis paniculata shows a broad range of defense mechanism against microbes and pest through cyanogenesis, phytohormone activation, lignifications of cell wall, modification of secondary metabolites and long list of plants which shows medicinal property in India and China [9].

Extraction and crystallization of andrographolide 
Crystallization is the ideal method for the purification of compounds from the natural/ herbal extracts. It is the best, cheap and efficient method for extraction of pure solids from the impure solids using different solvents and solvent mixtures such as methanol, ethanol, ethyl acetate, chloroform, petroleum ether and acetone.
Variant factors such as solvent solubility, solvent solubility temperature, type of solvents, pre - assessed solubility data determining polymorph formation and specific conditions under which extraction procedure to be performed plays an innate role for efficient andrographolide extraction [4].

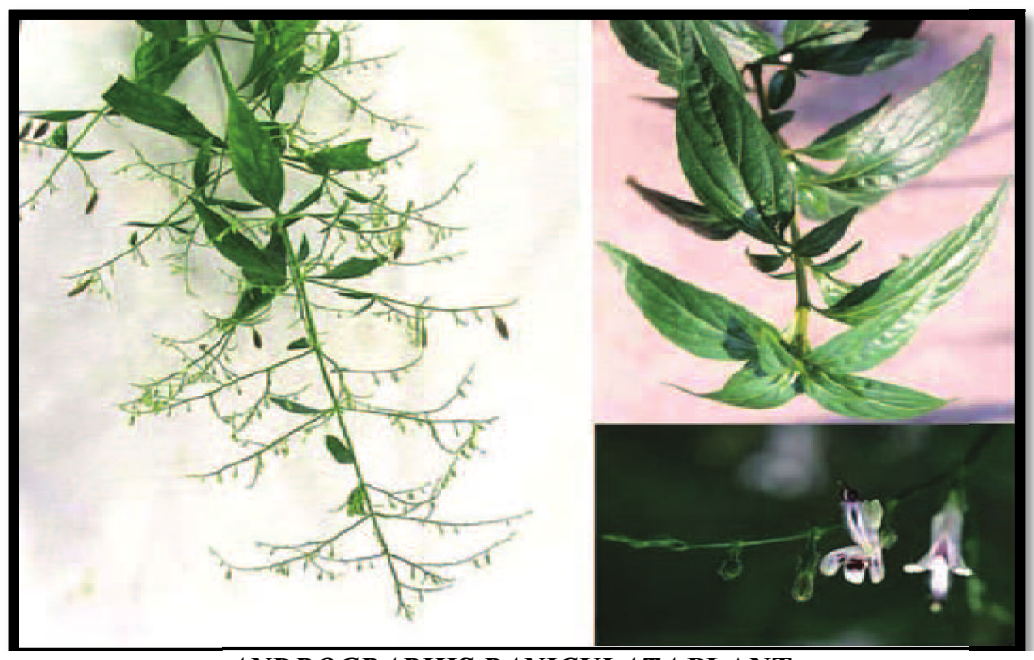

Source: https://plants.usda.gov/java/ClassificationServlet?source=profile\&symbol=ANPA2\&display=31

\section{Chemical and physical properties of} andrographolide

Andrographolide, an active component extracted using organic solvents methanol or ethanol which exhibits various physical, chemical and biological properties. Andrographolide, which is grouped as unsaturated tri-hydroxy lactone has the molecular formula of C20H30O5. Chemically it is dissolvable in the different organic solvents such as methanol, ethanol, acetone, acetic acid and pyridine normally utilized for phytochemicals extraction protocols. It derives physical absorption property of absorbing ultra-violet rays at
$223 \mathrm{~nm}$ holding $228-230$ 'C melting point [4]. Different extraction methods including soxhlet extraction method and hydrotropic microwave assisted are implemented to extract andrographolide, further followed by column chromatography in order to expel any subjected impurities thereof [4]. The leaves of Andrographis paniculata contains maximum concentration of active constituent Andrographolide, homo andrographolide, andrographosterol and andrographone while seeds contains minimum amount; its average content varied from 12.44 to $34.52 \mathrm{mg} / \mathrm{g}$ in a dried leaves found maximum at 90-120 days. The 
andrographolide crystals were observed in cube geometry in the size range of 30$40 \mathrm{~mm}$ using scanning electron microscopy and inverted microscopy [4].

\section{In-vitro propagation of andrographis paniculata}

Tissue culture is the orderly growth of different plant's tissues supplementing with nutritive growth medium containing various hormones including IAA, NAA under aseptic conditions under controlled lab conditions. Commercial propagation of medically important endemic plants has explored recently compared to past due to availability of modern techniques such as micro-propagation and tissue culture. Micro-propagation of Andrographis Paniculata is an important technique in order to select, multiply and conserve the indigenous medicinal plant to obtain the maximum concentration of active constituent andrographolide. ${ }^{[2,5,6]}$ The explant is any part of plant; which in-vitro can be subjected to either callus formation or organogenesis by supplementing with nutritional media comprising of plant growth hormones. Shoot tips, cotyledons, nodal segments, leaves, internodes and root segments were chosen as explants subjected for in-vitro growth [5, 6, 7]. Different sterilization protocols including primary and secondary surface sterilization of explants was performed using Tween 20 and Sodium hypochlorite to ensure aseptic growth of explants [6]. Murashige and skoog medium, an ideal nutritive medium to support in-vitro growth was chosen to grow the explants; different plants growth hormones namely 6 Benzyl adenine (BA), Cytokinin, 2ip (Iso-pentanyl), kinetin were sourced as an enrichment agents with or without NAA(Napthoxy acetic acid) and IBA(Indole-3-Butyric acid) as growth promoter/regulators [6]. Agar, a gelling agent and Sucrose as a carbon source along with the media were subjected for growth under laboratory conditions [7].

\section{Anti-bacterial and anti-fungal activity of andrographolide extract}

Bacteria, a prokaryote shows pathogenic or non-pathogenic nature to plants, animals and human beings. In developing countries, bacterial infections are persistently growing and gaining resistance against broad range of therapeutic agents such as antibiotics, monoclonal antibodies, combined drugs etc. Anti-bacterial activity screening of predominant pathogens including $P$. Aerugenosa, P vulgaris, E.coli, Bacillus subtillis, Salmonella typhi, Klebsielle pneumonia strains against andrographolide extract could be tested. Superbugs, resistant against number of antibiotics through plasmid inheritance are pre-dominant pathogens continuously rise by from $14.3 \%$ in 1987 to $60 \% 2006$ [8]. Several Gram negative strains which gained high resistance to carbepam group of antibiotics 
are known to cause threatening infections leading to notable morbidity or mortality [8]. The therapeutic drugs rendered ineffectiveness against various infectious agents; while an ancient approach utilizing plants preparation in medicine holds a prominent place to cure skin infections across the world especially in Asian continent such as Malaysia, India and china $[9,12]$. Higher plants are screened for antibacterial activity and anti-fungal property which could serve as a potential factor for discovering broad range of drugs [9]. Andrographis Paniculata plant extract namely andrographolide, an active constituent infer miraculous antagonist activity against wider range of microbiome. Dissolvability of active constituent exerting anti-microbial property was checked as positive in ethanol, methanol, acetone, pyridine and acetic acid while negative solubility in water andether which was further screened for determining the zone of inhibition through methanol (Fresh and dried leaves) and ethanol extracts containing andrographolide $[\mathbf{3}, \mathbf{4}, \mathbf{1 1}]$.

Anti-fungal property of andrographolide forms
Over the period of past 20 years, fungal infections has been dramatically inclined gaining resistance against the anti-fungal drugs which arises a new horizon to develop new drugs for challenging fungal strains [6]. The baseline for new drug development underlies the ancient ethnobotanical knowledge and ethnopharmacological exploration through implementation of modern scientific techniques [6]. Several fungal strains including dermatophytes (Trichophyton mentagrophytes (IMR T-44), Trichophyton rubrum (ATCC-28188), Microsporum canis (ATCC-36299), non dermatophyte (Aspergillus niger (IMR A-102)) and yeasts (Candida albicans (ATCC-90028), Candida krusei (IMR C-368), Candida tropicalis (IMR C-353)) were tested to determine anti fungal activity of different chemical forms of andrographolide [6]. Spore germination assay was subjected to determine the \%spore germination and \%spore germination inhibition while broth microdilution assay for obtaining the minimum inhibitory concentration and minimum fungicidal concentrations of various andrographolide forms $[6,7]$.

Table 1: Determination of the Inhibitory zone $(\mathrm{mm})$ using methanol extract of fresh and dried leaves

\begin{tabular}{|c|c|c|c|c|c|}
\hline S. No. & Name of pathogens & $\begin{array}{l}\text { Fresh leaf methanol } \\
\text { extract (IZ) mm }\end{array}$ & $\begin{array}{l}\text { Dry leaf methanol } \\
\text { extract (IZ) mm }\end{array}$ & $\begin{array}{l}\text { Kanamycin } \\
\text { (IZ) mm }\end{array}$ & $\begin{array}{l}\text { Ampicillin } \\
\text { (IZ) } \mathbf{~ m m}\end{array}$ \\
\hline 1. & Bacillus subtillis & 15 & 20 & 18 & 13 \\
\hline 2. & Staphylococcus & 5 & 13 & 20 & 18 \\
\hline 3. & Klebsiella pneumoniae & 10 & 18 & 15 & 18 \\
\hline 4. & Salmonella typhi & 9 & 12 & 15 & 13 \\
\hline 5. & Escherichia coli & 13 & 16 & 15 & 16 \\
\hline 6. & Enterobacter faecalis & 10 & 17 & 17 & 15 \\
\hline 7. & Pseudomonas aeruginosa & 8 & $\mathbf{R}$ & NS & NS \\
\hline
\end{tabular}


Table 2: Minimum Inhibitory Concentration and Minimum Fungicidal Concentration of DCM and MEOH of Andrographis Paniculata whole plant [6]

\begin{tabular}{|c|c|c|c|c|}
\hline Fungal Strains & $\mathrm{MIC}(\mathrm{mg} / \mathrm{ml})$ & $\mathrm{MIC} \mathrm{(mg/ml)}$ & MFC (mg/ml) & MFC (mg/ml) \\
\hline & DCM & МЕОН & DCM & МЕОН \\
\hline Trichophyton Mentagrophytes & 200 & 200 & 300 & 250 \\
\hline Trichophytum rubrum & 200 & 200 & 300 & 250 \\
\hline Microsporum Canis & 100 & 200 & 250 & 250 \\
\hline Candida Albicans & 100 & 200 & 250 & 250 \\
\hline Candida krusei & 250 & 200 & 300 & 350 \\
\hline Candida Tropicalis & 100 & 150 & 250 & 250 \\
\hline Aspergillus Niger & 250 & 150 & 250 & 250 \\
\hline
\end{tabular}

MIC $=$ Minimum Inhibitory Concentration, $\mathrm{MFC}=$ Minimum Fungicidal concentration, $\mathbf{D C M}=\mathbf{D i c h l o r o m e t h a n e , ~} \mathrm{MEOH}=$

Anti - oxidant activity of

\section{andrographolide}

Free radical is a molecule which has more than one unpaired electron found in environment, food, vehicle fumes, cigarette, smoke, baked food, drugs and air pollution. It is causation agent for variety of cardiovascular disorders, memory loss, cancer, cataracts and oxidative stress ${ }^{[13]}$ Overproduction of free radicals serves as the mediator to damage the cell structures such as cell wall, DNA, proteins, lipids and other bio-molecules which undergo self oxidation by inhibiting oxidation of important biological molecules [16]. Secondary metabolites present in the plant exclusively act as free radical scavenger through binding, stabilizing and prevent the oxidative reactions which damage the body's cell [15]. DPPH, Hydrogen peroxide radical, B carotene leaching activity were the targeted oxidative factors against which anti-oxidant activity is measured [14, 15]. Different extracts isolated using organic solvent are analyzed comparatively with natural antioxidants such as ascorbic acid; methanolic extract of andrographolide exhibit high rate of stabilization of the free radicals. It is relevantly effective on iso-proterenol induced myocardial oxidative stress when administered with APHE extracts [13]. The $\mathrm{IC}_{50}$ is the effective concentration extract to scavenge $50 \%$ of DPPH or stable free radicals [16]. Different extracts such as hexane, DCM, ethanol and methanol extracts were subjected to analysis determining results at certain time durations [16].

$\mathrm{IC}_{50}$ concentration can be analyzed by:

$\%$ inhibition of free radicals/DPPH activity

$$
=\mathbf{A}-\mathbf{B} / \mathbf{A} * \mathbf{1 0 0}
$$

Where A= Optical density of blank, B= Optical density of sample. [7.4]

Anti- cancer property of andrographolide extract

Cancer, a common endemic disease condition in which malignant tissue exhibits evasive proliferation potential due occurrence factors such as immune sensitivity, lifestyle, stress, anxiety, genetic mutations, selective pressure and many others [17]. Several factors influence the rapid uncontrolled outgrowth of tissue due 
metastasis, inhibition of apoptosis, evasive growth, self sufficiency in proliferating signals and insensitivity of growth inhibitory signals [18]. Andrographolide has shown potent anti-cancer activity for different proliferating cell lines such as breast, lungs, leukaemia and melanoma through action on the genes predominantly coding affecting the inhibition of growth factors (EGFR, Tfr's), matrix metalloproteinase (MMP's), cell signalling, focal adhesion, tight junction pathway, apoptosis, cell cycle regulation and activation of transcription factors(P53, Caspase cas9) [18]. Andrographolide and its analogues show anti-tumor property following the mechanisms of apoptosis and cell cycle arrest. In cancerous cell lines, andrographolide influences the reactivation of apoptotic mechanism by inducing caspas-3 and p53 which further inhibited $\mathrm{Nf-kb}$ (major transcription factor controlling cell apoptosis and proliferation) leading to cell death in human neuroblastoma cells. It acts as a leading factor in combined effect with flouracil for phosphorylation of P53, activation of caspase $3,8,9$, disruption of mitochondrial membrane potential and increase in the release of cytochrome $\mathrm{c}$ as a result of reactivation process and also acting as antineoplastic drug which prevents side effects of chemotherapy. [18].
Andrographolide affects human breast cancer cells and attenuated endothelial cell motility and tumor-endothelial cell interaction, which suppressed the tumor growth by arresting cell cycle arrest at G2/M phase and induced apoptosis by caspase dependent pathway [18, 20]. Caspase-3, cysteine - aspartate proteases are activated as a downstream effect or which leads breakdown of cellular proteins leading to cellular apoptosis in HT-29 colorectal cancer cell line and HL-60 human leukaemia cell line via following mitochondrial-mediated pathway. [20, 21]. Several inducible factors contributes to transcription activation of Matrix metalloproteinase MMP's enzyme, NF-kb transcription factor and Toll like receptors (TLR's) which collectively functions for the metastasis and infiltration of the various cancers including colon, breast, lungs cancer etc [19]. Colon cancer, a predominant cancer is the cause of imbalance in dietary patterns which leads to uncontrolled cell growth due to noninhibition of EGF (Epidermal growth factor), invasive cell metabolism, blocking of apoptosis, cell cycle dys-regulation leading to altered outgrowth condition [19]. It has anti-proliferation effects by increasing secretion of inhibitory protein p16, p53, p21 and ROS inhibitory and regulatory protein cyclin $\mathrm{D}, \mathrm{CDK} 2,1,4$ $[19,20]$. 
Autophagy, a physiologic process involves sequestration of the cellular components including unfolded proteins and membranous organelles packed into lysosome for the degradation. Autophagic cell death known as Type 2 programmed cell death showed one of the prominent anti-cancer therapies.

The

Andrographolide-induced cell cytotoxicity is attributed to autophagy which is associated with cyclophilin D mediated mitochondrial permanent ability transition pore (MPTP) mode of action [21].

\section{Anti-diabetic and anti-malarial activity}

Diabetes mellitus is a leading metabolic disorder resulting from insulin secretion disorder, insulin order or both which is relatively associated cause of oxidative stress and increased production of reactive oxygen species including hydroxyl radical, superoxide radical and hydrogen peroxide radical [22]. Streptozotocin, a cytotoxic factor to pancreatic islets induced hyperglycaemic index for referencing study in response to andrographolide. The streptozotocin treated model relatively showed decreased weight due to deformation/ degradation of muscles by the action of proteinases following the gluconeogenesis process; the dose dependent treatment of andrographolide due presence of flavanoids, saponins, polyphenols and terpenoids comparatively reduced the hyperglycaemic index after administration of certain time duration. Andrographolide comparatively increased insulin sensitivity, augmenting glucose dependent insulin secretion, stimulating regeneration of pancreatic cells in terms of number and size of cells [22]. Aqueous and ethanol extracts of andrographolide shows determinant decrease in the blood glucose level relatively in glucose loaded and alloxan induced diabetic rat showing potent anti-diabetic activity. ${ }^{[23]}$ Rodent malaria parasite; Plasmodium Berghei was subjected to the ICR mice intra-peritoneal to determine anti-malarial activity. The aqueous extract of andrographolide drug activity is administered in the body followed by analysis of parasitaemia using blood smear from tail blood from D0 to D4. The degree of suppression showing antimalarial activity was encountered against $P$. Berghei in dose independent manner with maximum inhibitory activity at $200 \mathrm{ul} / \mathrm{kg}$ at $82.46 \%$ suppression as compared with negative control group [24].

\section{Anti-Diarrhoea activity}

The Andrographis Paniculata aerial extract mainly from leaves extraction using ethanol, 1-butanol or chloroform showed inhibitory activity against E.coli enterotoxin secretion causing the diarrhoea syndrome in model organisms compared to the aqueous extract. Various isoforms constituents of andrographolide in extract including diterpine lactones and 
neoandrographolide

apart

from

andrographolide

shows

relevant

antisecretory effect on enterotoxin production in E.coli induced diarrhoea in in-vivo model organisms [25]. On a comparison study, the two strains of E.coli; heat liable and heat stable toxins were administered in the model organisms in order to determine relative effect in relation to loperamide drug. Three isoforms were administered in model organism namely andrographolide, neoandrographolide and deoxyandrographolide which was compared for the beneficial inhibitory effect on secretion of the toxins by the E.coli [25]. On a comparative account the andrographolide and neoandrographolide showed potent inhibitory effect as loperamide synthetic drug on LT toxin than ST toxin; the deoxyandrographolide show relevantly low effect on the ST and LT toxins in $18 \mathrm{hrs}$ of maximum inhibition. Inhibitory action of drug is conferred by blockage of intestinal secretion induced by heat liable E.coli through decreased stimulation of adenylate cyclase by heat liable E.coli enterotoxin. Incubation of murine macrophages with andrographolide inhibited bacterial endotoxin induced nitrite accumulation on the base of time and dose dependent manner [25].

\section{Anti-hyperlipidemic activity}

Hyperlipidemic condition is an underlying cause of atherosclerosis and various blockages due lipid deposition through increased concentration of various lipid forms such as VLDL(Very low density lipoprotein), LDL (Low density lipoprotein), TG (Triglycerides), PL (Phospholipid) and LP (Lipoprotein) in plasma at an inclined rate. The PHLA (Phospholipase) and LCAT (Lecithin cholesterol acetyl transferase) enzymes play a key role in regulating lipid (Cholesterol) content in blood and tissues. Trition induced model organism rat were fed with high lipid diet and control with the normal saline and groundnut oil [26]. Andrographolide extract and Gemfibrozil were macerated with $0.2 \%$ aqueous acacia gum suspension and administered orally for lipid decreasing effect. The animals were sacrificed for liver extraction of TG, PL, $\mathrm{TC}$ and protein for the estimation of lipolytic activity of extracts. The administered extracts and Gemfibrozil showed considerable reduction in levels of VLDL (-28\%), LDL-TC (-38\%), PL ($33 \%)$, TG (-29\%) and Apo-LDL (-30\%) respectively in model adult rats while on contrary basis the reduced compound intervention leads to increased concentration of TG, TC, PL and proteins respectively [26]. The enzymes mainly PHLA and LCAT were inhibited at a notable rate $38 \%$ and $49 \%$ respectively. Indirectly the cholesterol reduction activity was recorded by determining the excretion 
of bile acids mainly choline (-41\%) and deoxycholic acid $(-51 \%)$ in faecal excretion in the model organisms [26].

\section{Anti-platelet activity}

Platelet,a factor responsible for regulation of primary homeo-stasis, pro-inflammatory factor and cyclooxygenase(COX) enzyme expression factor. Epinephrine, ADP and collagen acts as agonist for activation of platelet through receptor binding P2X1, $\mathrm{P} 2 \mathrm{Y} 1, \mathrm{P} 2 \mathrm{Y} 12$ receptors as well as thromoboxane A2(TXA2) undergoing change of platelet shape induced by collagen $[27,28]$. The administration of andrographolide on platelets accounts for reversible receptor reaction, drug metabolizing enzymes and inducing genetic variations which conclusively leads to disaggregation. This effect was studied in a group of young volunteers which showed differed result on the basis of factors such as COX pathway, $\mathrm{P}$ selectin and gender variability which can be subjected to suspected bleeding tendency, including thrombosis [27]. The application of Andrographis paniculata extract subjected to moderate clot lytic activity against the blood clots in in-vivo model organism and in-vitro conditions; Clot lyses activity is therefore due to active substance andrographolide which can be subjected to clot lyses in patients [28].

\section{Allergic mediator}

The Andrographis paniculata extract and phyto-active andrographolide anaphylaxis potential role in RBL-2H3 (basophilic leukaemia) cell line was determined. The sensitized and non-sensitized $\operatorname{IgE}$ stimulation of mast cells resulting in release of histamine, B-Hexasoaminidase, Leukotriene C4 (LTC4) and tryptase contribution was analyzed. The ovalalbumin adjuvant with challenge antigen was injected intraperitoneally followed by subcutaneous injection of andrographolide, DMSO and ovalalbumin for test, vehicle and positive control [29]. RBL-2H3 cultured in EMEM conditioned with FBS were harvested and transferred to microtiter plate to determine the extracts activity as allergic compound releaser. Sensitized IgE incubated with high andrographolide extracts considerably induced release of histamine, B Hexosoaminidase, LTC 4 and tryptase when compared to low dose 0.2, 2 and $20 \mathrm{mg} / \mathrm{ml}$. On a comparative note in the non-sensitized $\operatorname{IgE}$, the low concentration of andrographolide failed to induce inflammatory compounds when compared to high content $10 \mathrm{mg} / \mathrm{ml}$ with DMSO reference. However increased release of tryptase was noted in the $0.1-10 \mathrm{mg} / \mathrm{ml}$ dose concentration of andrographolide when compared to DMSO [29]. 


\section{METHODOLOGY}

\section{Preparation of Extract}

The fresh leaves were obtained from the Andrographis paniculata which was dried under a shade for a day further subjected under hot air oven under 60'C. It was powdered with 40 meshes and stored for further use. The $50 \mathrm{gm}$ dried powder was macerated in the methanol overnight. The marc was packed in the Soxhlet and extracted with respected solvents (chloroform, methanol, acetone, petroleum ether) (10 cycles in each case). The extracts were collected carefully and solvents were removed under vacuum [32].

\section{Phytochemical analysis}

The phytochemical analysis is performed using different solvent extracts including petroleum ether, chloroform and acetone $[30,31,33]$.

\section{Materials, Reagents and Methods}

1. Sample: Leaves samples of Andrographis Paniculata were obtained, dried and powdered using blender. The samples were kept in solvents for $24 \mathrm{hrs}$.

2. Solvents: Petroleum ether, chloroform and acetone used for isolation of phytochemicals.

3. Extraction, Isolation and testing methods: $20 \mathrm{ml}$ acetic acid solution was filtered and plant powders with each solvent forms the test solution

4. Phenolic compounds: The treatment of one drop ferric chloride to the petroleum ether extract, chloroform and acetone extract. Yellow colour denotes presence of phenolic compounds.

5. Flavanoids: Different extracts were treated with one gram of magnesium powder, 1N concentrated HCL; Yellow colour determines the presence of flavanoids.

6. Alkaloids: Acetone, petroleum ether and chloroform extract were treated with $2 \mathrm{~N} \mathrm{HCL}$; formation of aqueous layer followed by decanting. Addition of 1 to 2 drops of Mayer's reagent in the remaining solution. Appearance of turbidity or precipitate like conditions denotes presence of alkaloids.

7. Steroids: Different extracts were taken and addition of 3 drops of acetic anhydride and 2 drops of concentrated $\mathrm{H} 2 \mathrm{SO}$. Colour change to green indicates the presence of steroids.

8. Saponins: The test solution of chloroform, acetone and petroleum extracts was shaken after addition of water. Foaming of the test solution detects the presence of saponins.

9. Tannins: Different crude solvent extract were treated with 2 drops of lead acetate solution, presence of tannins is detected by white precipitates

10. Anthroquinone: Take $1 \mathrm{ml}$ of plant extract, add few drops of $20 \%$ of ammonia solution. The appearance of 
pink colour precipitates indicates the present of anthroquinone

11. Terpenoids: Take $0.5 \mathrm{ml}$ of plant extract, add chloroform and concentrated sulphuric acid. Formation of red brown colour interface indicates the presence of terpenoids.

12. Steroids: Take $10 \mathrm{mg}$ of plant extract, add $1 \mathrm{ml}$ of concentrated $\mathrm{H}_{2} \mathrm{SO}_{4}$ slowly through sides of test tube. Indication of dark reddish green colour indicates the presence of steroids.

13. Glycosides: Take $2 \mathrm{ml}$ of plant extract, $3 \mathrm{ml}$ of chloroform and $10 \%$ of ammonia solution. Appearance of pink colour denotes the presence of glycosides.

14. Cardiac glycosides: Take $0.5 \mathrm{ml}$ of plant extract, $2 \mathrm{ml}$ of glacial acetic acid and few drops of $5 \%$ ferric chloride. It was underplayed below on the $1 \mathrm{ml}$ sulphuric acid. Brown ring indicates the presence of cardiac glycosides.

15. Xantho-proteins: Take $2 \mathrm{ml}$ of plant extract, add few drops of nitric acid. The yellow colour change determines presence of xanthoproteins.

MTT assay: MTT is colorimetric cell viability/ cytotoxicity assay which is dependent on mitochondrial respiration and indirectly serves to access energy capacity of cell. It is one of the most economic, reliable, accurate, easy and most convenient assay for determination of cytotoxicity.
- The enzymatic reaction involves conversion 3-[4,5-dimethylthiazole-2yl]-2,5-diphenyltetrazolium bromide (MTT) to MTT-formazan is catalyzed by mitochondrial succinate dehydrogenase.

- Different cell lines namely Ramos, Granta, HF-1 and SUDHL4 were taken for test to determine the $\mathrm{IC}_{50}$ (Inhibitory concentration where the $50 \%$ of cells are affected) against the control in the micro-titre plate.

- Cells were seeded at a density at $2 * 10$ raise to 4 cells/ 90 ul in a microtitre plate and treated with $10 \mathrm{ul}$ concentration of AGP (Andrographolide) for 1 to $4 \mathrm{hr}$ time duration at $37^{\prime} \mathrm{C}$ [34].

After treatment, 20ul of $5 \mathrm{mg} / \mathrm{ml}$ MTT solution were added to each aspirates, followed by formazan crystals produced in the cells were solubilised in DMSO(Di-methyl sulfoxide),WST dye are required as materials.

- Absorbance was measured @490nm using microplate reader from different companies.

- Results were expressed as percentage cell viability in comparison to control; The reduction of MTT is possible in metabolically active cells, the measurement of cell viability is exercised $[34,35]$. 
- DPPH assay: DPPH assay is aimed at recognising the antioxidant potential of andrographolide based on the reduction capacity of DPPH free stable radical. DPPH (2,2-diphenyl-1- picrylhydrazyl) is a stable free radical due to delocalization of spare electron on the whole molecule. When DPPH, a stable form in violet colour when reacts with the hydrogen donor androgropholide which further leads to disappearance of violet colour.

- The antioxidant activity of A.paniculata using different extracts, 200ul sample extract and different concentration of freshly prepared ascorbic acid in different test tubes.

- Add 50ul of $\mathrm{HCl}(1.0 \mathrm{M})$ was added to the sample extract containing ascorbic acid.

- The final volume is made upto 500ul with absolute methanol.

- $500 \mathrm{ul}$ of DPPH $(0.004 \%)$ was added into methanolic extract to all the test tubes and incubated in dark and cold environments for 30 minutes to complete the reaction [38].

- The absorbance was measured @517nm.

- The percentage of free radical scavenging was calculated using formula:

$$
\begin{gathered}
=(\mathrm{Ab}-\mathrm{As}) / \mathrm{Ab} * 100 \\
\text { Where, } \\
\mathrm{Ab}=\text { Absorbance of the blank }
\end{gathered}
$$

As $=$ Absorbance of the standard or sample extract
Ascorbic acid $=$ Positive control

- \% of Free radical scavenging is plotted against the concentration of plant extracts and the value of $\mathrm{IC}_{50}$ (i.e. the percentage of plant extract required to inhibit the formation of the free radical by $50 \%$ ) was calculated from the regression line obtained. Test was carried out in triplicate and the value considered were average of three test procedures [38]

\section{RESULTS AND DISCUSSION}

As per above qualitative analysis, the Andrographis Paniculata may possess following phytochemicals in different amount:

Different organic solvents utilized for the phytochemical analysis through chemical reaction method: $[3, \mathbf{3 0}]$.

In Table 2, the phytochemical analysis was carried out using different organic solvents to determine the best organic solvents for the extraction of shaded dried leaves of Andrographis paniculata which can be used to extract the phytochemicals. Notable difference has been observed in different extracts; water extract shows the presence for phenols, flavonoids, proteins, steroids, xanthoproteins, anthroquinone, alkaloids and saponins. Methanol extract and water extract shows comparative common absence of glycosides or cardiac glycosides while along with carbohydrates and terpenoids absence in water extracts. 
Ethanolic extract denotes the presence of maximum phytochemicals which may be one of the ideal solvent for isolation, extraction and determination of phytochemicals [31].

In Table 3, the phytochemical analysis reveals the presence of phenolic compounds, alkaloids, flavonoids, saponins in the petroleum ether while showing the absence of steroids and tannins. The comparative analysis for acetone extract for the presence of phenolic compounds, alkaloids, flavonoids, saponins, steroids and tannins remained nil as compared chloroform extract which shows presence of stated phytochemicals [30]. MTT assay, a cell cytoxicity assay was administered on four cell lines including NALM-6, K562, A549 and MCF-7 using AGP (andrographolide) drug at different concentrations for 24 to $48 \mathrm{hrs}$. The core determination of cell cycle analysis and nuclear fragmentation assay based on staining method was performed. NALM-6 cells were found most sensitive cell line when administered after treatment with andrographolide drug which further was washed, harvested followed by the treatment with $70 \%$ ethanol and incubated for 30min in PBS containing $50 \mathrm{ug} / 1$ propidium iodide stain, $100 \mathrm{ug} / \mathrm{l}$ of PBS solution. The stained cells were analyzed using 10 raise to 4 cells on a flow cytometer. The cytotoxicity of andrographolide was determined in terms of percentage of cells in each phase of cell cycle; the AGP mediated apoptosis was evidenced through elevated number of cells at $\mathrm{G} 1 / \mathrm{G} 0$ phase in compare to control PBMC. The re-confirmation test was performed taking most sensitive cell line NALM-6 to determine the cell cycle arrest(an assurance factor for apoptosis) which further resulted into cell cycle arrest at $\mathrm{G} 1 / \mathrm{G} 0$ phase not $\mathrm{G} 2 / \mathrm{M}$ phase. The results were confirmed when the AGP showed a low cytotoxic effect on PBMC, which further interpreted the non-harmful effect of AGP on the healthy cells as compared to the cancerous cell lines. Nuclear fragmentation provides basis for the apoptosis event which was examined in the NALM-6 cell line through DAPI staining. The nuclear fragmentation pattern was analyzed by the treatment of andrographolide IC50; it resulted into increased nuclear fragmentation along with the increased number of apoptotic body formation resulting apoptosis as compared to control. The results of nuclei fragmentation were positive by appreciable amount of nuclear fragmentation in the cells [34]. The DPPH is the ideal assay utilized for the determination of the antioxidant potential of Andrographis Paniculata extract which was ideally prepared using different organic solvents [38]. The DPPH generally utilized as 
substrate for evaluating antioxidant potential [39] The high antioxidant potential is crucially dependent on the type of solvent utilized for the extraction. Three solvents namely water, ethanol and hexane were utilized for the extract preparation which was tested for highest antioxidant activity. The activity against free stable radicals depends on the presence of free hydroxyl group containing substance in plants extracts i.e. flavonoids. This method is critically based the reduction of methanolic extract DPPH solution in presence of strong antioxidant which results in formation of non-reducing DPPH [39]. Water, a most polar solvent and the flavonoids with highest free hydroxyl group showed highest free radical scavenging ability to eradicate the free radicals by oxidation reaction. The high polarity solvent inundates elevated levels of natural anti-oxidant activity against stable free radicals [38]. The reaction with aqueous antioxidant andrographolide extract with methanolic DPPH results into reduction of DPPH into DPPH-H, a yellow coloured diphenylpicyrlhydrazine [39]. The $\mathrm{IC}_{50}$ value (the concentration of required extract that inhibits the formation of free radicals by $50 \%$ ). The IC50 concentration were calculated using different Andrographis Paniculata solvent extracts from linear regression curve. On a comparative account the least $\mathrm{IC}_{50}$ was recorded for aqueous extract of $A$. Paniculata at $4.42 \mathrm{mg} / \mathrm{ml}$ while ethanolic extract was recorded at $6.84 \mathrm{mg} / \mathrm{ml}$. The aqueous polar solvent water extract holds promising scavenge activity against free radical which results from the oxidation of bio molecules such as proteins, lipids, amino acids, nucleic acid and peroxidation of lipids [38-40].

Table 3: Phytochemicals analysis using different organic solvents

\begin{tabular}{|c|c|c|c|c|}
\hline S. No & Phytochemical constituents & Water extract & Methanol & Ethanol \\
\hline 1. & Phenols & + & +++ & ++ \\
\hline 2. & Flavonoids & + & +++ & ++ \\
\hline 3. & Carbohydrates & - & ++ & + \\
\hline 4. & Proteins & + & +++ & +++ \\
\hline 5. & Alkaloids & + & +++ & ++ \\
\hline 6. & Saponins & +++ & ++ & + \\
\hline 7. & Tanins & - & +++ & ++ \\
\hline 8. & Anthroquinons & ++ & ++++ & ++ \\
\hline 9. & Terpenoids & - & ++ & + \\
\hline 10. & Steroids & + & +++ & ++ \\
\hline 11. & Glycosides & - & - & ++ \\
\hline 12. & Cardiac glycosides & - & - & ++ \\
\hline 13. & Xanthoproteins & + & ++ & ++ \\
\hline
\end{tabular}

- Negative, + slightly positive, ++ moderate positive, +++ highly positive [12.6]. 
Table 4: Determination of Phytochemicals using petroleum ether, acetone and chloroform

\begin{tabular}{|c|c|c|c|c|}
\hline S. No & $\begin{array}{c}\text { Phytochemical } \\
\text { constituents }\end{array}$ & Petroleum ether & Acetone & Chloroform \\
\hline 1. & Phenolic compounds & + & - & + \\
\hline 2. & Flavonoids & + & - & + \\
\hline 3. & Alkaloids & + & - & + \\
\hline 4. & Steroids & - & - & + \\
\hline 5. & Saponins & + & - & + \\
\hline 6. & Tanins & - & - & + \\
\hline
\end{tabular}

\section{CONCLUSION}

The applicative paradigm of ayurvedic herb extract Andrographis paniculata shows upward inclination in therapeutic usage dating back from ancient skin diseases to the latest dangerous disease like cancer. This herb shows the promising medicinal application due to presence of variety of phytochemicals. Andrographolide, an antagonism action oriented active compound in the disease condition like diabetes, inflammatory disease, cancer, virus infections, malaria, diarrhoea, bacteria and fungi infections, high plasma lipids, cardiac disease and various others; the potent usage in medicinal application is much evident from the phytochemicals property analysis in-vivo and in-vitro laboratory model organisms and established tissue cell lines.Established tissue culture technique demarks the barrier for laboratory analysis on various disease conditions in model organisms. The MTT and DPPH assays determined the potential for cellular cytotoxicity and free radical scavenging activity in cancerous cell lines on a dose dependent manner. The active constituent diterpine lactone shows relative down-regulation of severity in the hyperlipidemic and anti coagulant conditions which may serve as a base line for the development of the combined drug (Ayurvedic and synthetic drug combined formulation) or Intra-venous injections in varying drug concentrations for the therapeutic treatment of Cardiac arrest or cardiac blockages and anti-obese drug in future.

\section{REFERENCES}

[1] Deepthi Agarwal, A New Anticancer drug from the leaves of Andrographis paniculata, Journal of Global Biosciences, Volume 4, Number 5 2015.

[2] Meenu Sharma and R G Sharma, Identification Purification and Quantification of Andrographolide from Andrographis paniculata (BURM F.) NEES by HPTLC at different stages of life cycle of crop, Journal of Current chemical and Pharmaceutical Sciences, SC 3(1), Pages 23-22, 2013.

[3] Priyanka Das and Alokkumar Srivastav, Phytochemical Extraction and Characterization of the leaves of Andrographis Paniculata for its 
Antibacterial, Antioxidant, Antipyretic and Antidiabetic activity, Innovative Journal of Innovative Research in Science, Engineering and Technology, Vol. 3 Issue 8, 2014.

[4] Dilip Jadhao and Bhaskar Thorat, Purification (Crystallization) of bioactive ingredient andrographolide from Andrographis paniculata, World Journal of Pharmacy and Pharmaceutical Sciences, Volume 3, Issue 10, Page 747-743, 2014.

[5] A.S Deshmukh et.al, In-vitro multiple shoot induction in Andrographis Paniculata, International Journal of Current Microbiology and Applied Sciences, Issue 6, Page 791-795, 2018.

[6] V. Aruna and T. Pullaiah, In-vitro shoot multiplication of Medicinally important plant Andrographis Paniculata lineate Nees via Nodal explants, European Journal of Medicinal Plants, Issue 17(3), Page 17,2016

[7] Rafica Akhtar et.al, Efficient In-vitro Micro propagation of Andrographis Paniculata and Evaluation of AntiBacterial activity from Its Crude Protein Extracts, 6(4), Page no. 231$241,2015$.

[8] Anamika Gupta, Anti-Bacterial activity of Andrographis Paniculata (Burm. F.) Wall ex. Nees leaves against Clinical pathogens, Journal of Pharmacy Research 7, Page 459-461, 2013

[9] Noor Rian et.al, In-vitro Screening of five local medicinal plants for antibacterial activity using disc diffusion method, Tropical Biomedicine, 22(2), Page 165-170, 2005.

[10]A. P. Lipton et.al, Assessment of Antibacterial Activity and Detection of Small Molecules in Different Parts of Andrographis Paniculata, Journal of Theoretical and Experimental Biology, 6(3 and 4), Page 235-241, 2010.

[11]Mohammad Nor Omar et.al, AntiFungal activity of Andrographis Paniculata extracts and active principles against skin pathogenic fungal strains in vitro, Pharmaceutical Biology, 2012.

[12]A. N. Lokesha et.al, Anti-fungal activity of Andrographis Paniculata and andrographolide, Journal of Pharmacognosy and Phytochemistry, 4(2), Page 08-10, 2015.

[13]S.K Ojha et.al, Antioxidant activity of Andrographis Paniculata in Ischemic Myocardium of Rats, Global Journal of Pharmacology, 3(3), Page 154-157, 2009.

[14]Rastogi Archit et.al, A detailed analysis of the Antioxidant activity of Medicinal Plant Andrographis Paniculata, International Journal of 
Drug development and Research, 6(1), Page 231-238, 2014.

[15] N.K Warditiani et.al, Antioxidant activity of Andrographolide in Bitter herbs using DPPH scavenging, JHSM UNUD Journals, Vol 1 No 1, 2017.

[16]Punam Shinde et.al, Study of antioxidant and antimicrobial activities of Andrographis Paniculata, Asian Journal of Plant Science and Research, 4(2), Page 31-41, 2014.

[17] Mahendran Vanaja et.al, Anti-Cancer activity of Andrographis Paniculata extract against Neuroblastima(IMR-32) and Human Colon(HT-29) Cancer cell line, World Journal of Pharmacy and Pharmaceutical Sciences, 2015.

[18] Swati Tripathi et.al, Andrographolide and analogues in Cancer Prevention, Frontiers in Bioscience, Elite 7, Page 292-304, 2015.

[19]JIAN XU et.al, Andrographolide suppresses proliferation of Human Colon Cancer SW620 cells through TLR4, NF-kB, MMP-9 signalling pathway, Oncology letters 14, Page 4305-4310, 2017.

[20]Fahad Khan et.al, Andrographolide exhibits Anti-Cancer Potential Against Human Colon Cancer Cells by Inducing Cell Cycle Arrest and Programmed Cell Death via Augmentation of Intracellular Reactive
Oxygen Species, Nutrition and Cancer, 2018.

[21] Wei Chen et.al, Andrographolide induces autophagic cell death in human liver cancer cells through cyclophilin D-mediated mitochondrial permeability transition pore, Carcinogenesis, Vol. 33 No.11, Page 2190-2198, 2012.

[22]Ramya Premanath and Lakshmidevi Nanjaiah, Antidiabetic and Antioxidant potential of Andrographis Paniculata Nees. Leaf ethanol extract in Streptozotocin induced diabetic rats, Journal of Pharmaceutical and Applied Sciences, Vol. 5(01), Page 069-076, 2015.

[23]Mohammad A. Rashid and A. M. Sarwaruddin Chowdhury, Antidiabetic activity of Andrographis Paniculata, Dhaka University Journal of Pharmaceutical Sciences, 6(1), Page 15-20, 2007.

[24]B.A.H ZAINAL ABIDIN and L. JANG SING, Anti-Malarial activity of Andrographis Paniculata in Mice, Vol. 5(2), Page 545-550, 2008.

[25] Mashkoor A Choudhry and Vandita Srivastav, Antidiarrhoeal Activity of Diterpines of Andrographis Paniculata(Kal-megh) against Escherichia coli Enterotoxin in in vivo Models, International Journal Crude 
Drug Research, No. 4, Page 273-283, 1990.

[26] Shishir Srivastav et.al, Lipid Lowering Potential Andrographis Paniculata, The Journal of Phytopharmacology, 3(2), Page 124-129, 2014.

[27] Tichapa Sirikarin et.al, The Effects of Andrographis Paniculata on Platelet activity in Healthy Thai Volunteers, Evidence-Based Complementary and Alternate Medicine, 2018.

[28] $\mathrm{S} \mathrm{K}$ Afsar et.al, Effect of Andrographolide on in-vitro Thrombolytic activity, Pharmacologia 4, 2013.

[29]Edwin Jothie Richard et.al, Is Andrographis Paniculata extract and Andrographolide anaphylactic , Toxicology reports, 2017

[30] Sithara N.V et.al, Phytochemical analysis of Andrographis Paniculata using different solvents, European Journal of Biotechnology and Biosciences, Vol. 4 Issue 8, Page 2830, 2016.

[31]Bhargavi B and Kalpana Kaloori, Preliminary Phytochemical Analysis of Different Solvent Extract of Andrographis Paniculata(Burm. F.) Wall Ex Nees., International Journal of Pharmacy and Biological Sciences, Vol.8 Issue.4, Page 311-314, 2018.

[32]M. Rajni et.al, A Rapid Isolation of Andrographolide from Andrographis
Paniculata

Nees(Kalmegh),

Pharmaceutical Biology, Page 204209, 2000.

[33] Mayuri Thanwar, A phytochemical Investigation on Andrographis Paniculata, Journal of Chemical and Pharmaceutical Research, 7(10), Page 822-827, 2015.

[34]Santanu Paul et.al, Andrographolide induced Apoptosis in NALM-6 cells mediated through Cell cycle arrest and Apoptosis, Pharmacognosy Journal, Vol. 10 Issue 2, 2018.

[35] Enrique Chacon et.al, in-vitro methods in Pharmaceutical Research, 1997.

[36]Savita Bhalla et.al, Mitochondrial Mediated Apoptosis in Lymphoma Cells by Diterpine Lactone Andrographolide, The Active Component Of Andrographis Paniculata, Clinical Cancer Research, 16(9), 2010.

[37]Meenu Sharma and Shuman Joshi, Comparision of Anti-oxidant activity of Andrographis Paniculata and Tinospora Cordifolia Leaves, Journal of Current Chemical and Pharmaceutical Sciences, Page 1-8, 2018.

[38] Tanushree Saha et.al, Investigation of Phytochemicals, Antioxidant and Antimicrobial activity of Andrographis Paniculata Leaf and Stem Extracts, 
Advances in Bioscience and

Biotechnology, Page 149-162, 2017.

[39] Poornananda Madhav Naik,

Polyphenol Composition and

Antioxidant Activity of Andrographis
Paniculata L.Nees, Mapana Journal Science, Page 33-46, 2014.

[40]Enrique chacon, John j. Lemasters, in vitro methods in pharmaceutical research, 1997. 